\title{
Separation, identification and quantitation of ceramides in human cancer cells by liquid chromatography-electrospray ionization tandem mass spectrometry
}

\author{
M. Fillet ${ }^{\mathrm{a}, *}$, J.-C. Van Heugen $^{\mathrm{b}}$, A.-C. Servais ${ }^{\mathrm{a}}$, J. De Graeve ${ }^{\mathrm{b}}$, J. Crommen $^{\mathrm{a}}$ \\ ${ }^{a}$ Department of Analytical Pharmaceutical Chemistry, Institute of Pharmacy, University of Liège, CHU, B36, B-4000 Liège 1, Belgium \\ ${ }^{\mathrm{b}}$ Department of Environmental Toxicology, University of Liège, CHU, B35, B-4000 Liège 1, Belgium
}

\begin{abstract}
Ceramides are important intracellular second messengers that play a role in the regulation of cell growth, differentiation and programmed cell death. Qualitative and quantitative analysis of these second messengers requires sensitive and specific analytical methods to detect endogenous levels of individual ceramide species and to differentiate between them. Nine synthetic ceramides were separated by liquid chromatography coupled to tandem mass spectrometry on a $\mathrm{C}_{18}$ bonded silica column. The lipids were eluted in gradient elution mode using a mixture of water, acetonitrile and 2-propanol as mobile phase. They were detected by reaction monitoring performed on positive ion electrospray generated ions. Collision-induced fragmentations conducted on ceramides produced a well characteristic product ion at $m / z$ 264, making multiple reaction monitoring (MRM) well suited for various ceramides quantitative measurements. After optimization of the extraction step, the proposed methodology was able to identify and quantify different ceramide species issued from human cancer cells. The method could be validated for $\mathrm{C}_{16}, \mathrm{C}_{18}$ and $\mathrm{C}_{20}$ ceramides, quantified at the nanogram level. The validation exhibits good results with respect to linearity, accuracy and precision. (c) 2002 Elsevier Science B.V. All rights reserved.
\end{abstract}

Keywords: Ceramides; Sphingolipids; Lipids

\section{Introduction}

In addition to their major structural role as a barrier for cell permeability and as a matrix for the association of membrane proteins, sphingolipids play a key role in the signal transduction and cell regulation.

Sphingomyelin hydrolysis to ceramides occurs through the action of sphingomyelin-specific forms of phospholipase $\mathrm{C}$ called sphingomyelinases. In addition to the breakdown of sphingomyelin to

\footnotetext{
*Corresponding author. Tel.: +32-4-366-4354; fax: +32-4366-4347.

E-mail address: marianne.fillet@ulg.ac.be (M. Fillet).
}

ceramide, a mechanism for the generation of ceramide exists through the action of ceramide synthase. Accurate and precise analytical methods, able to quantify selectively the various ceramide molecular species at low concentrations, are crucial for elucidating their function and metabolism.

Various experimental approaches have demonstrated that ceramides are key signaling molecules generated in response to a variety of stresses that mediate growth arrest, differentiation, senescence, apoptosis or an immune response [1-6]. Nonetheless, their mechanisms of action remain largely unknown. In view of the increasing interest in sphingolipid metabolites, sensitive and specific methods are required to measure their endogenous levels. 
Structurally, the ceramides exhibit a long amino alcoholic chain covalently bound via an amide linkage to a fatty acyl moiety (cf. Fig. 1). These molecules can vary in length, degree of unsaturation and hydroxylation, giving rise to a complex and diverse group of compounds. These lipids have proven to be very difficult to analyse due to their apolar nature, diversity and relatively low levels in biological samples.
Until now, the diacylglycerol (DAG) kinase assay is the most commonly used procedure for ceramide quantitation $[7,8]$. The DAG kinase phosphorylates ceramide into a radioactive product which is detected by thin-layer chromatography (TLC). The principle limitations of the DAG kinase assay as well as the TLC measurement are their requirement of high sample volumes and their lack of discrimination capability between different ceramide species. Sever-

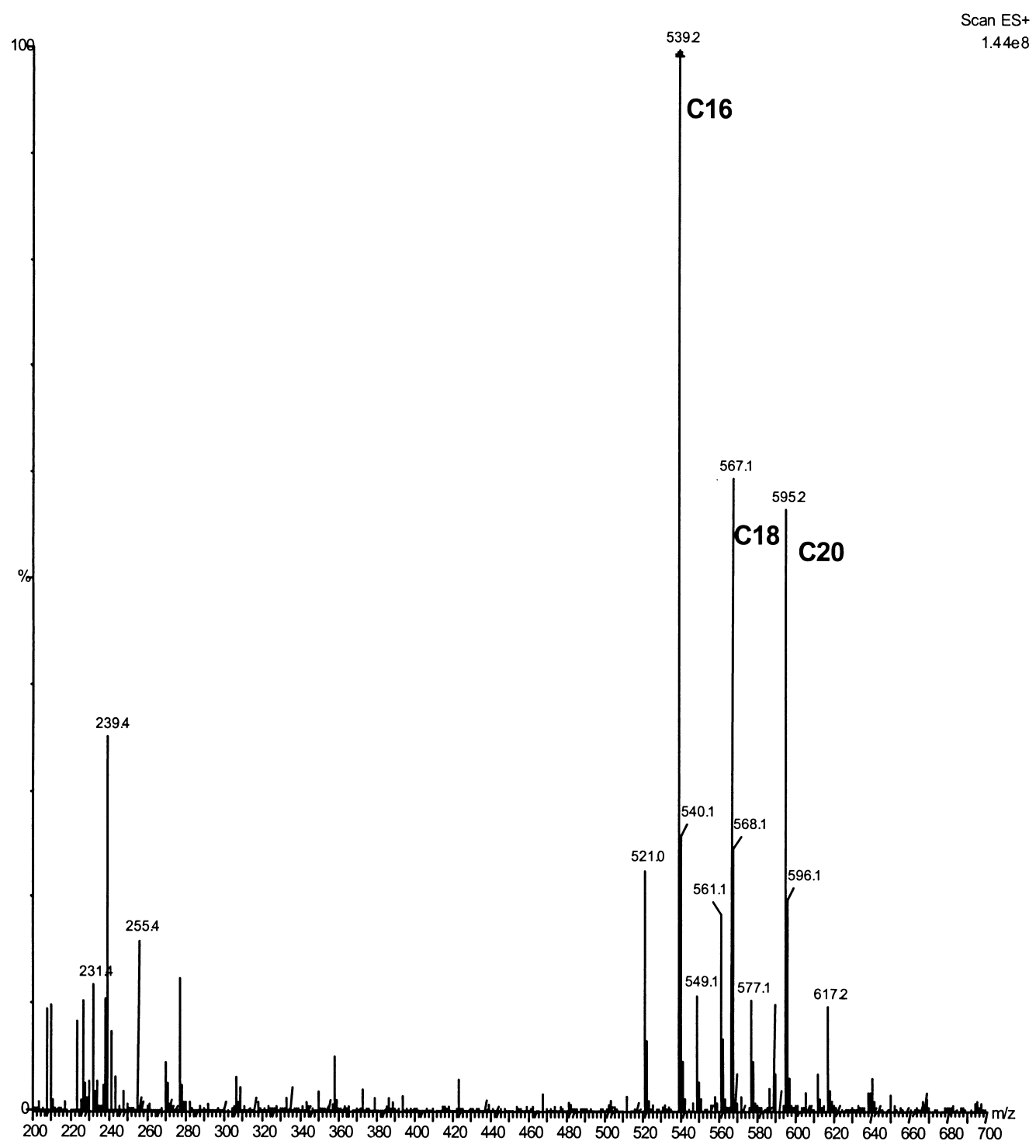

Fig. 1. MS spectra of $\mathrm{C}_{16}, \mathrm{C}_{18}$ and $\mathrm{C}_{20}$ ceramides. 
al other methods are also available for quantitation of sphingolipid metabolites by liquid chromatography (LC). Since the ceramides lack a chromophore group to allow a sensitive UV measurement, fluorescent or radioisotope detection after derivatization were perferred [9-11] All the above described procedures are time-consuming and tricky derivatization steps might often be source of error hampering the accurate determination of the ceramides levels. The use of an evaporative light-scattering detector for the ceramide visualization and identification provides direct analysis without any prior derivatization [12].

In the last few years, mass spectrometry methodologies have been developed for the detection of ceramides [13-17]. This technique is also a powerful tool for determining endogenous, physiologically active compounds because of its high selectivity and sensitivity. Electrospray ionization mass spectrometry (ESI-MS) has been successfully used for several years for the analysis of peptides and proteins and it has been more recently extended to the analysis of other species like carbohydrates and lipids $[15,17]$.

This work is focused on the separation and the identification of standard ceramides by liquid chromatography-electrospray ionization tandem mass spectrometry (LC-ESI-MS-MS). The extraction procedure of lipids from human cells was optimized in order to obtain sufficient sensitivity. In human cancer cells, the endogenous ceramides were identified and quantitatively measured. Finally, the procedure was validated for $\mathrm{C}_{16}, \mathrm{C}_{18}$ and $\mathrm{C}_{20}$ ceramides and some analytical data are presented.

\section{Experimental}

\subsection{Chemicals}

$\mathrm{C}_{2}, \mathrm{C}_{6}, \mathrm{C}_{8}, \mathrm{C}_{10}, \mathrm{C}_{12}, \mathrm{C}_{14}, \mathrm{C}_{16}, \mathrm{C}_{18}$ and $\mathrm{C}_{20}$ ceramides were obtained from Acros (Gell, Belgium).

Water, acetonitrile, 2-propanol, ethanol, formic acid were of HPLC grade from Merck (Darmstadt, Germany).

Nitrogen (alphagaz 1) and argon (alphagaz 2) were purchased from Air Liquide (Milmort, Belgium).

\subsection{Instruments and methods}

The high-performance liquid chromatograph (HPLC) is a HP 1100 series; it is equipped with a binary pump, a vacuum degasser, a thermostated column compartment and an autosampler, all from Agilent Technologies (Waldbronn, Germany). The HPLC separations were performed at $70^{\circ} \mathrm{C}$ on a RP $\mathrm{C}_{18}$ Nucleosil AB column $(5 \mu \mathrm{m}, 70 \times 2 \mathrm{~mm}$ I.D. $)$ from Macherey-Nagel (Düren, Germany). The mobile phase was a gradient mixture formed as follows: $\mathrm{A}$, water-acetonitrile-2-propanol $(8: 1: 1, \mathrm{v} / \mathrm{v} / \mathrm{v}) ; \mathrm{B}$, acetonitrile-2-propanol $(9: 1, \mathrm{v} / \mathrm{v})$. The steps of the gradient program were: 0 min 35:65 (A-B), 2 min 35:65 (A-B), 7 min 10:90 (A-B), 13 min 10:90 (A-B), $15 \min 0: 100(\mathrm{~A}-\mathrm{B}), 16 \min$ 35:65 (A-B), $18 \min 35: 65$ (A-B). The mobile phase was degassed for $10 \mathrm{~min}$ in an ultrasonic bath before use. The flow-rate was $0.450 \mathrm{ml} / \mathrm{min}$. The sample volume injected was $6 \mu l$.

MS detection was carried out using a Ultima triple quadrupole instrument (Micromass, Manchester, UK) operating under MassLynx 3.5 and configured with a Z-spray electrospray ionization source.

Source conditions were as follows: positive ion electrospray, capillary voltage $3.0 \mathrm{kV}$, cone voltage $14 \mathrm{~V}$, source temperature $145^{\circ} \mathrm{C}$, desolvation temperature $450^{\circ} \mathrm{C}$, cone gas flow (nitrogen) $94 \mathrm{l} / \mathrm{h}$ and desolvation gas flow (nitrogen) $552 \mathrm{l} / \mathrm{h}$. The MSMS fragmentation of the molecular ion was achieved with a collision energy of $27 \mathrm{eV}$ (collision gas:argon).

\subsection{Preparation of standards}

Standard solutions for ESI-MS-MS optimization were prepared by dissolving the ceramides in a mixture of ethanol-formic acid (99.8:0.2, v/v) to reach a concentration of $1 \mu \mathrm{g} / \mathrm{ml}$.

\subsection{Cellular lipid extraction}

Cells were rinsed twice with ice-cold phosphatebuffered saline (PBS), scraped in PBS, centrifuged at $800 \mathrm{~g}$ and the resulting pellet was homogenized in distilled water by sonication. An aliquot of the cell homogenate was taken for protein determination.

Then, $10 \mathrm{ng}$ of $\mathrm{C}_{12}$ ceramide (as internal standard) was added to the cell lysate (the latter corresponding 
to $500 \mu \mathrm{g}$ of proteins). Lipids were extracted using the Folch's partition with a mixture of chloroformmethanol $(2: 1, \mathrm{v} / \mathrm{v})$, centrifuged at $1500 \mathrm{~g}$, and finally washed with chloroform-methanol-water $(3: 48: 47, \mathrm{v} / \mathrm{v} / \mathrm{v})$. The organic phase was evaporated near to dryness under a gentle stream of dry nitrogen. The samples were reconstituted by vortexing with $200 \mu l$ of a mixture ethanol-formic acid (99.8:0.2) until complete dissolution.

To avoid any loss of lipids, the whole procedure was performed in siliconized glassware.

\subsection{Cell preparation}

HCT116 human colon carcinoma cells were cultured in McCoy medium (Life Technologies, Inc.) supplemented with $10 \%$ fetal bovine serum, $1 \% 200$ $\mathrm{m} M$ L-glutamine, 100 units $/ \mathrm{ml}$ penicillin and 100 $\mu \mathrm{g} / \mathrm{ml}$ streptomycin. Ovcar ovarian carcinoma cells, U937 lymphoid cells and MCF7 A/Z breast cancer cells were maintained in RPMI 1640 medium (Life Technologies) supplemented with $10 \%$ fetal bovine serum, $1 \% 200 \mathrm{~m} M$ L-glutamine, 100 units $/ \mathrm{ml}$ penicillin, and $100 \mu \mathrm{g} / \mathrm{ml}$ streptomycin. The cells were maintained at $37^{\circ} \mathrm{C}$ in a $5 \% \mathrm{CO}_{2}$ atmosphere.

\subsection{Preparation of spiked samples for the validation}

Before the extraction process, five cell lysates (corresponding to $500 \mu \mathrm{g}$ of proteins from HCT116 cells) were spiked with a constant amount of internal standard (10 ng of $\mathrm{C}_{12}$ ) and with increasing amounts of $\mathrm{C}_{18}$ and $\mathrm{C}_{20}(0,2,4,8$ and $16 \mathrm{ng})$ and of $\mathrm{C}_{16}(0$, $5,10,20$ and $50 \mathrm{ng}$ ). The lipids extraction were conducted according to the procedure described in Section 2.4.

\section{Results and discussion}

\subsection{Optimization of the MS detection}

The MS analysis of ceramides was first investigated by direct introduction of the reference compounds dissolved in an ethanol-formic acid (99.8:0.2) mixture using the electrospray interface in the positive mode of ionization.
For each of the tested ceramide, two main peaks were observed corresponding respectively to the $[\mathrm{M}+\mathrm{H}]^{+}$and $\left[\mathrm{M}+\mathrm{H}-\mathrm{H}_{2} \mathrm{O}\right]^{+}$ionic species (Fig. 1). Parameters such as the capillary and cone voltages, as well as the cone and the desolvation gas flows were optimized in order to generate the highest protonated molecular ion under a stable spray (cf. Section 2.2).

\subsection{MS fragmentation of the ceramides}

It has been shown previously that collision-induced dissociations (CID) of ceramides in electrospray, positive ion mode, mainly generate the characteristic product ions of $\mathrm{m} / \mathrm{z} 264$ and $\mathrm{m} / \mathrm{z} 282$, respectively, whereas other sphingosine metabolites provided different fragmentation pathways [14]. These fragments resulted from the loss of the $\mathrm{N}$ linked fatty acid moiety and one or two molecules of water (cf. Fig. 2). This dissociation pattern could be confirmed for ceramides species varying in this $\mathrm{N}$ linked fatty acid moiety (2-20 carbons into the chain).

The collision energy was optimized in order to reach a maximum intensity for the fragment ion of $\mathrm{m} / \mathrm{z} 264$ resulting in a minimum response for the
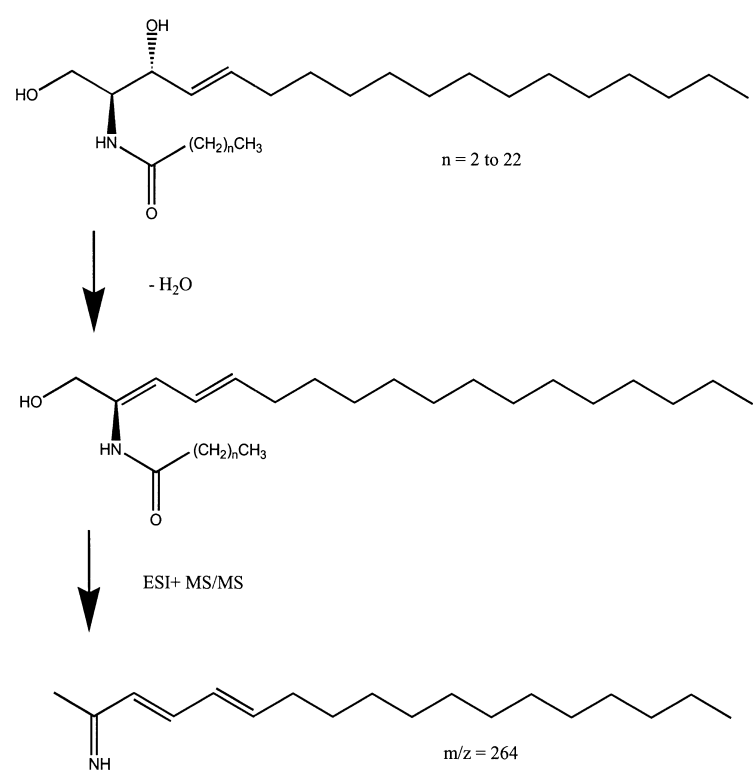

Fig. 2. Structure of ceramide and fragmentation process. 
molecular ionic species (Fig. 3). The fragment ion with the highest $\mathrm{m} / \mathrm{z}$ ratio $(\mathrm{m} / \mathrm{z} 264)$ was selected for quantitative MS detection in the multiple reaction monitoring (MRM) mode. As MRM is based on the transition involving the specific molecular ion and a characteristic fragment ion, high detection selectivity as well as high signal-to-noise ratios could be obtained providing a clean reversed-phase (RP) LCMS-MS-MRM chromatogram.

To increase the sensitivity, two MRM signals were traced and added for the evaluation of each ceramide. The first MRM signal is $[\mathrm{M}+\mathrm{H}]^{+} \rightarrow m / z 264$ while the second corresponds to the $[\mathrm{M}+\mathrm{H}-$ $\left.\mathrm{H}_{2} \mathrm{O}\right]^{+} \rightarrow m / z 264$ transition.

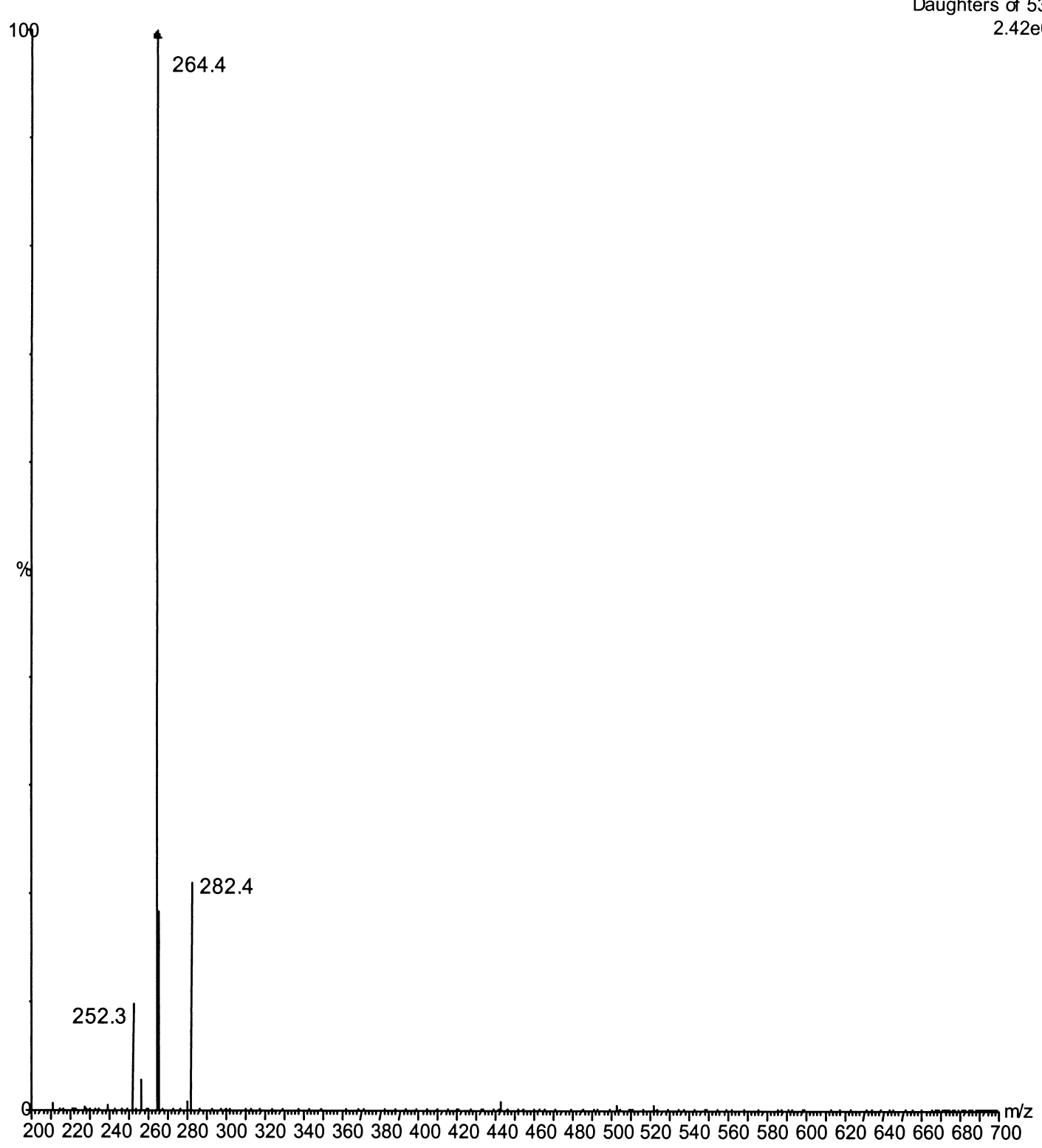

Fig. 3. MS-MS spectrum of $\mathrm{C}_{16}$ ceramide. 


\subsection{Selection of the LC conditions}

The next step of this study concerned the optimization of the LC separations of the nine commercialy available ceramides $\left(\mathrm{C}_{2}, \mathrm{C}_{6}, \mathrm{C}_{8}, \mathrm{C}_{10}, \mathrm{C}_{12}, \mathrm{C}_{14}, \mathrm{C}_{16}\right.$, $\mathrm{C}_{18}$ and $\mathrm{C}_{20}$ ceramides, respectively).

The best separation of ceramide species was obtained on a reversed-phase column $\left(\mathrm{C}_{18}\right.$ Nucleosil $\mathrm{AB}$ column). Among a large number of potential buffers and organic solvents compatible with the MS-MS detection, the mixture water-acetonitrile2-propanol provided the best results in terms of selectivity. A multiple step gradient (cf. Section 2.2) has been developed in order to reach high selectivity for the compounds with short migration times. The MRM chromatogram recorded for the ceramide synthetic mixture is depicted in Fig. 4.

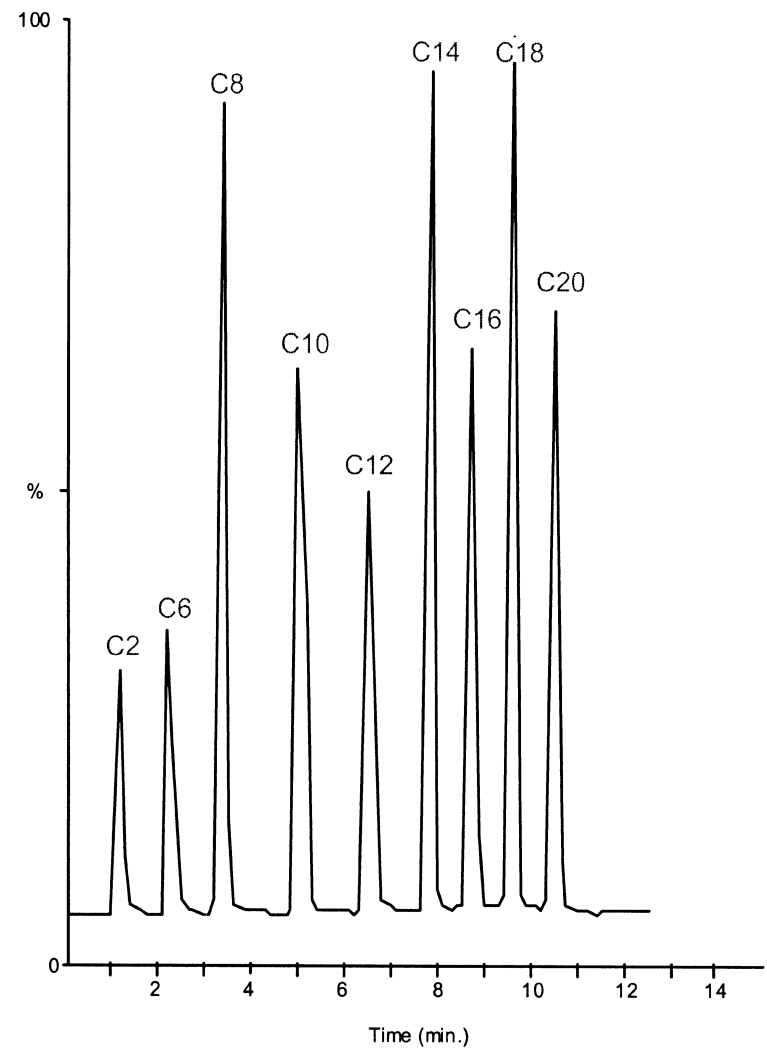

Fig. 4. MRM chromatogram of nine standard ceramides $(1 \mu \mathrm{g} /$ ml) by LC-ESI-MS-MS. All conditions described in Section 2.2.

\subsection{Comparison of the ceramides patterns observed in four cancer cell lines}

Once the LC and MS conditions were fully optimized, identification of endogenous ceramides was achieved using four different cell lines: HCT116 human colon carcinoma cells, Ovcar ovarian carcinoma cells, U937 lymphoid cells and MCF7 A/Z breast cancer cells. In all of them, five ceramide species $\left(\mathrm{C}_{16}, \mathrm{C}_{18}, \mathrm{C}_{20}, \mathrm{C}_{22}, \mathrm{C}_{24}\right)$ could be retrieved but in different ratios. The MRM chromatograms of the endogenous ceramides retrieved in the different cell lines are reported in Fig. 5.

\subsection{Method validation}

In order to generate quantitative results for those $\mathrm{C}_{16}, \mathrm{C}_{18}$ and $\mathrm{C}_{20}$ ceramides, calibration curves were established by spiking different amounts of the corresponding natural ceramides $\left(\mathrm{C}_{16}, \mathrm{C}_{18}\right.$ and $\left.\mathrm{C}_{20}\right)$ to HCT116 cell lysate (amount corresponding to 500 $\mu \mathrm{g}$ of proteins). For quantitative assessment, a constant amount (10 ng) of non-naturally occurring $\mathrm{C}_{12}$-ceramide internal standard was added to the mixture before starting the lipid extraction.

All values were expressed as the ratio of the peak areas of the natural ceramide to that of the internal standard. This was done in order to cope for possible variations in the extraction yield or/and to compensate for some instabilities in the MS parameters, which could affect ionization efficiency and ion counts.

\subsubsection{Linearity}

Calibration graphs were constructed with five levels in the range $0-16 \mathrm{ng}$ for the $\mathrm{C}_{18}$ and $\mathrm{C}_{20}$ ceramides and in the range $0-50 \mathrm{ng}$ for the $\mathrm{C}_{16}$ ceramide. Three determinations were performed at each concentration level $(n=3)$. Linear regression lines were calculated by plotting normalised peak areas (ratios of peak areas of the natural ceramide to that of the internal standard) versus the spiked ceramide amount using the least-squares method with the hypothesis of homoscedasticity [18,19].

The linearity of the calibration curve was determined tracing each ceramide with two added MRM signals: $[\mathrm{M}+\mathrm{H}]^{+}$and $\left[\mathrm{M}+\mathrm{H}-\mathrm{H}_{2} \mathrm{O}\right]^{+}$to $\mathrm{m} / z$ 264. Straight lines and coefficient of determination 


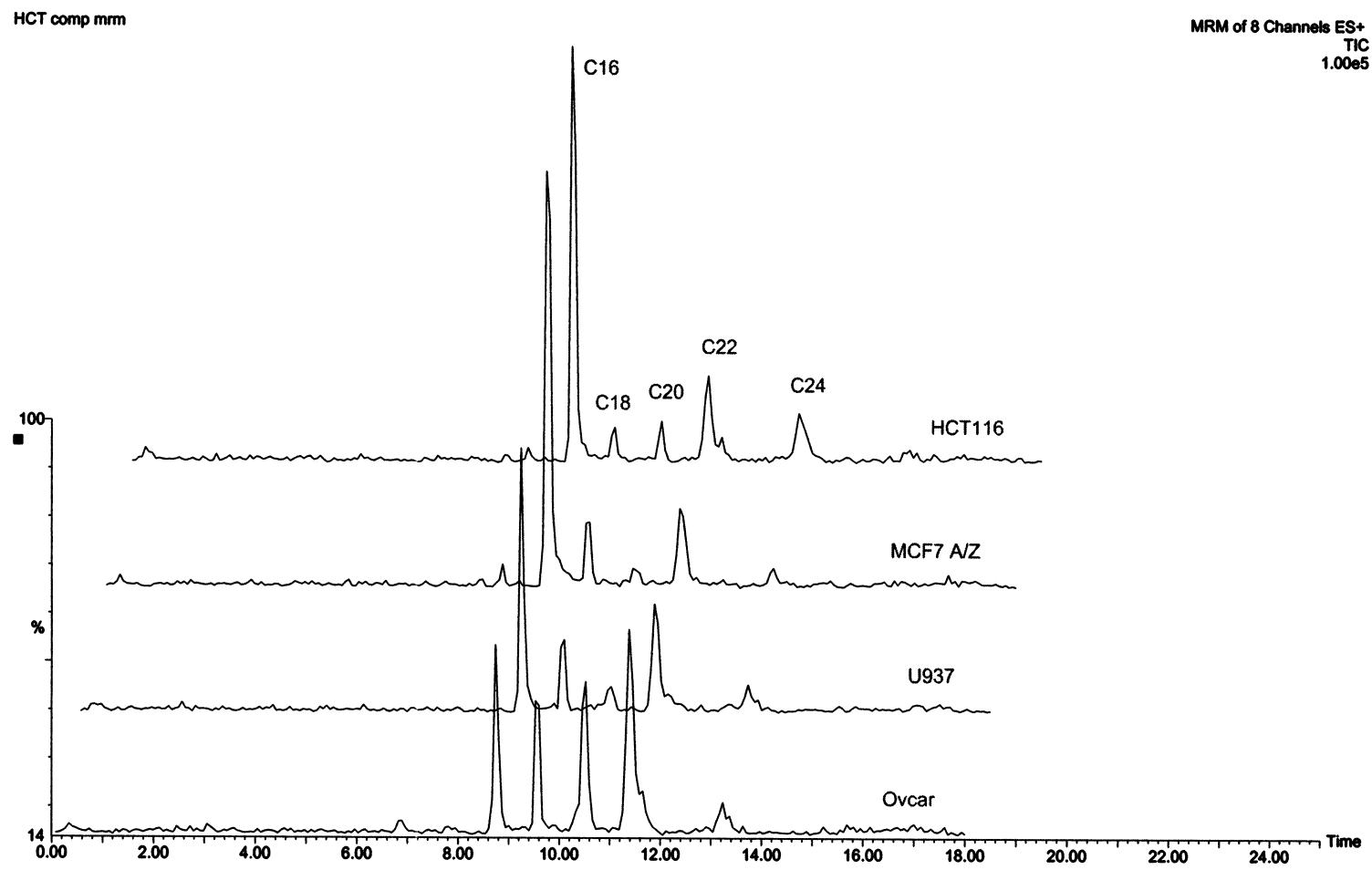

Fig. 5. MRM chromatogram of endogenous ceramides by LC-ESI-MS-MS in four cancer cell lines, HCT116 (colon), MCF7 A/Z (breast), U937 (lymphoid), Ovcar (ovarian). Time scale in minutes.

$\left(r^{2}\right)$ of 0.9976 for the $\mathrm{C}_{16}$ ceramide, 0.9973 for the $\mathrm{C}_{18}$ ceramide and 0.9977 for the $\mathrm{C}_{20}$ ceramide were obtained (cf. Fig. 6). The linearity was also confirmed by an analysis of the variance (ANOVA) $[18,19]$. The regression parameters are given in Table 1.

\subsubsection{Limits of detection and of quantitation}

Limits of detection (LOD) and quantitation (LOQ) correspond to signal-to-noise ratios of 3 and 10 , respectively.

The LOD, the lowest amount of $\mathrm{C}_{18}$ ceramide that could be detected, was $0.073 \mathrm{ng}$ for $500 \mu \mathrm{g}$ of HCT116 proteins, which corresponds to $124 \mathrm{fmol}$. The LOQ, the lowest amount of $\mathrm{C}_{18}$ ceramide that could be quantified was $0.245 \mathrm{ng}$, which corresponds to $413 \mathrm{fmol}$.

For the $\mathrm{C}_{16}$ ceramide, the LOD and the LOQ were 0.253 and $0.844 \mathrm{ng}$, respectively, for $500 \mu \mathrm{g}$ of HCT116 proteins. For the $\mathrm{C}_{20}$ ceramide, the LOD and the LOQ were 0.318 and $1.060 \mathrm{ng}$, respectively.

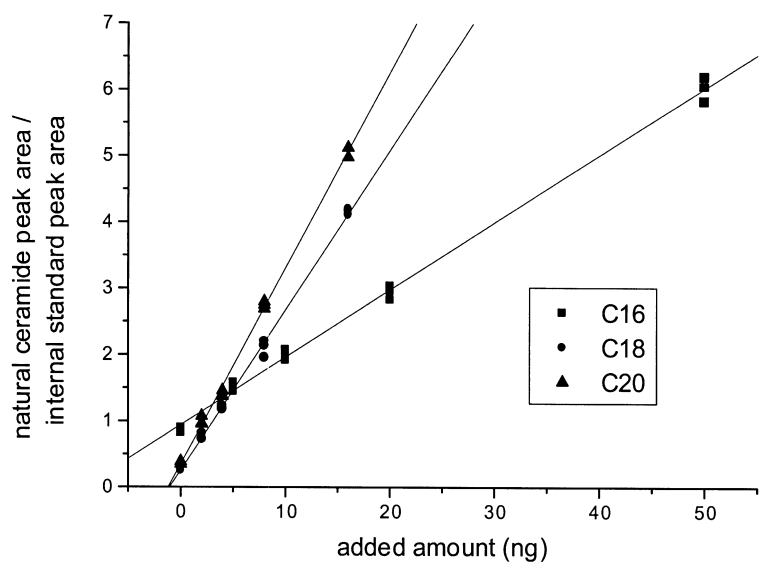

Fig. 6. Calibration curves for $\mathrm{C}_{16}, \mathrm{C}_{18}$ and $\mathrm{C}_{20}$ ceramides. 
Table 1

Validation results

\begin{tabular}{|c|c|c|c|}
\hline Validation criteria & $\mathrm{C}_{16}$ & $\mathrm{C}_{18}$ & $\mathrm{C}_{20}$ \\
\hline Calibration range (ng/500 $\mu \mathrm{g}$ proteins) & $0-50$ & $0-16$ & $0-16$ \\
\hline Calibration points & 5 & 5 & 5 \\
\hline Coefficient of determination $\left(r^{2}\right)$ & 0.9976 & 0.9973 & 0.9977 \\
\hline \multicolumn{4}{|l|}{ Accuracy $(k=3, n=15)$} \\
\hline Mean recovery $\pm \mathrm{CI}(\%)$ at $4 \mathrm{ng}$ added & ND & $102.8 \pm 5.5$ & $98.2 \pm 4.2$ \\
\hline Mean recovery $\pm \mathrm{CI}(\%)$ at $10 \mathrm{ng}$ added & $97.5 \pm 4.1$ & ND & ND \\
\hline Mean recovery $\pm \mathrm{CI}(\%)$ at $16 \mathrm{ng}$ added & ND & $104.6 \pm 4.6$ & $104.6 \pm 5.1$ \\
\hline Mean recovery $\pm \mathrm{CI}(\%)$ at $50 \mathrm{ng}$ added & $100.2 \pm 2.3$ & ND & ND \\
\hline \multicolumn{4}{|l|}{ Repeatability $(k=3, n=6, R S D \%)$} \\
\hline at endogenous level & 5.97 & 13.13 & 13.34 \\
\hline at $4 \mathrm{ng}$ added & ND & 4.26 & 3.46 \\
\hline at $10 \mathrm{ng}$ added & 4.43 & ND & ND \\
\hline at $16 \mathrm{ng}$ added & ND & 4.00 & 4.23 \\
\hline at $50 \mathrm{ng}$ added & 2.23 & ND & ND \\
\hline \multicolumn{4}{|l|}{$\begin{array}{c}\text { Intermediate precision } \\
(k=3, n=18, R S D \%)\end{array}$} \\
\hline at endogenous level & 10.26 & 13.43 & 18.54 \\
\hline at $4 \mathrm{ng}$ added & ND & 4.98 & 4.74 \\
\hline at $10 \mathrm{ng}$ added & 4.61 & ND & ND \\
\hline at $16 \mathrm{ng}$ added & ND & 4.68 & 4.32 \\
\hline at $50 \mathrm{ng}$ added & 3.87 & ND & ND \\
\hline LOD (ng/500 $\mu \mathrm{g}$ proteins) & 0.253 & 0.073 & 0.318 \\
\hline LOQ (ng/500 $\mu \mathrm{g}$ proteins) & 0.844 & 0.245 & 1.060 \\
\hline Estimation of endogenous & 9.226 & 1.043 & 1.165 \\
\hline level (ng/500 $\mu \mathrm{g}$ proteins) & & & \\
\hline
\end{tabular}

ND: not determined.

\subsubsection{Accuracy}

The method accuracy was determined at two different levels $(n=6)$ covering the same range as that used for linearity ( 4 and $16 \mathrm{ng}$ for $\mathrm{C}_{18}$ ceramide and $\mathrm{C}_{20} ; 10$ and $50 \mathrm{ng}$ for $\mathrm{C}_{16}$ ). Mean recoveries with confidence intervals ( $\mathrm{CI}$ at $P>0.05)$ are presented in Table 1. As the theoretical value of $100 \%$ was included in the confidence interval, the test procedure could be considered as accurate over the range studied.

\subsubsection{Precision}

Method precision was determined by measuring repeatability and intermediate precision (betweenday precision) $(n=6)$. The study was carried out during 3 days $(k=3)$, at three levels $(0,4$ and $16 \mathrm{ng}$ for $\mathrm{C}_{18}$ and $\mathrm{C}_{20}$ ceramides; 0,10 and $50 \mathrm{ng}$ for $\mathrm{C}_{16}$ ceramide). The RSD values were estimated from repeatability and intermediate precision variances, respectively $[19,20]$.

As depicted from the data of Table 1, acceptable results with respect to precision could be obtained. The RSDs at the endogenous level, which is close to the LOQ for $\mathrm{C}_{20}$ ceramide, are relatively high but still acceptable for analysis conducted on such biological samples.

\section{Conclusions}

The method developed for the separation of ceramides present in human cancer cells using a 
LC-ESI-MS-MS procedure was found to be linear, accurate, precise and sensitive to the nanogram level.

This method enables accurate and precise analysis for ceramides issued from relatively small samples providing a useful tool for signal transduction research. In the future, this procedure will be used for studying the changes of endogenous ceramides concentrations that could occur during cellular stress and apoptotic process.

\section{Acknowledgements}

A research grant from the Belgium National Fund for Scientific Research (FNRS) to one of us (M.F.) is gratefully aknowledged. Many thanks are also due to FNRS for its financial support.

\section{References}

[1] C.J. Gamard, G.S. Dbaibo, B. Lui, L. Obeid, Y. Hannun, J. Biol. Chem. 272 (1997) 16474.

[2] T. Okazaki, T. Kondo, M. Tashima, Cell Signal 10 (1998) 685.

[3] Y.A. Hannun, Science 272 (1996) 1855.

[4] L.M. Obeid, Y.A. Hannun, J. Cell Biochem. 58 (1995) 191.

[5] J.D. Fishbein, R.T. Dobrowsky, A. Bielawska, S. Garrett, Y.A. Hannun, J. Biol. Chem. 268 (1993) 9255.
[6] M.E. Venable, Y.L. Lee, M.J. Smith, A. Bielawska, L.M. Obeid, J. Biol. Chem. 67 (1995) 27.

[7] P.P. Van Veldhoven, W.R. Bishop, D.A. Yurivich, R.M. Bell, Biochem. Mol. Biol. Int. 36 (1995) 21.

[8] A. Olivera, J. Rosenthal, S. Spiegel, Anal. Biochem. 223 (1994) 306.

[9] A.H. Merrill, E. Wang, R.E. Mullins, W.C.L. Jamison, S. Nimkar, D.C. Liotta, Anal. Biochem. 171 (1988) 373.

[10] M. Previati, L. Bertolaso, M. Tramarin, V. Bertagnolo, S. Capitani, Anal. Biochem. 233 (1996) 108.

[11] A. Olivera, S. Speigel, Nature 365 (1993) 557.

[12] T. McNabb, A. Cremesti, P. Brown, A. Fischl, Anal. Biochem. 276 (1999) 242.

[13] F.M. Rubino, L. Zecca, S. Sonnino, Biol. Mass Spectrom. 23 (1994) 82

[14] M. Gu, J.L. Kerwin, J.D. Watts, R. Aebersold, Anal. Biochem. 244 (1997) 347.

[15] M. Mano, Y. Oda, K. Yamada, N. Asakawa, K. Katayana, Anal. Biochem. 244 (1997) 291.

[16] L.H. Couch, M.I. Churchwell, D.R. Doerge, W.H. Tolleson, P.C. Howard, Rapid Commun. Mass Spectrom. 11 (1997) 504.

[17] A. Karlsson, P. Michelsen, O. Goran, J. Mass Spectrom. 33 (1998) 1192.

[18] D.L. Massart, B.G.M. Vandeginste, S.N. Deming, Y. Michotte, L. Kaufman, Chemometrics: a Textbook, Elsevier, Amsterdam, 1988, p. 75 .

[19] J. Caporal-Gautier, J.M. Nivet, P. Algranti, M. Cuilloteau, M. Histe, M. Lallier, J.J. N'Guyen-Huu, R. Russoto, S.T.P. Pharma Prat. 2 (1992) 202.

[20] C. Hartmann, Analusis 22 (1994) M19. 